\title{
Agricultural soils strengthening employing humic acids and its effect on plant growth chilli pepper and eggplant
}

\author{
Fredy Colpas-Castillo" ${ }^{1 *}$, Arnulfo Tarón Dunoyer ${ }^{2 *}$, Jairo Mercado Camargo ${ }^{3}$ \\ ${ }^{1}$ Faculty of Exact and Natural Sciences, Department of Chemistry, Carbochemical Research Group. University of Cartagena, Colombia. \\ ${ }^{2}$ Faculty of Engineering, University of Cartagena, Colombia. ${ }^{3}$ Faculty of Pharmaceutical Sciences. University of Cartagena, Colombia.
}

\section{A B S T R A C T}

\begin{abstract}
The Humic substance has been recognized widely as a plant growth promoter because they induce changes in root, architecture and dynamics of growth which result in larger root size. The aim of this study was evaluating the effect Humic acids on the chili pepper (Capsicum annuum) and eggplant (Solanum melongena) plants growing in soils fertilized with urea. $200 \mathrm{~g}$ of soil were incorporated to the fertilizer once and the Humic acid in concentrations of $0.05 \%, 0.1 \%$ and $0.2 \%$. All measurements growths were carried out during 45 days growth. The finding shows that all treatments cause significant increases $(p<0.05)$ in the total area of roots. For the chili pepper, the multiple comparison tests of Tukey and Dunnett showed that there was a statistically significant difference between the control soils and the soils containing $0.1 \%$ and $0.2 \%$ of Humic acid. By the opposite, no statistical differences $(p>0.05)$ were observed among control soil and those containing $0.05 \%$ of Humic acid. Concerning the eggplant, significant differences were established $(p<0.05)$ between the control and samples incorporated with $0.1 \%$ and $0.2 \%$ of Humic acid. The Humic acids act as a growth biostimulant in chili pepper plants (Capsicum annuum) and eggplant (Solanum melongena).
\end{abstract}

Keywords: Chili Pepper; Coal; Eggplant; Humic Acids; Plant Growth.

\section{INTRODUCTION}

Humic acids (HA) are a fraction of the Humic substances (HS), formed by aromatic and polyaromatic nuclei, linked through aliphatic chains. These have a diversity of functional groups, which allow them to perform various functions in the soil-plant relationship (Pantoja et al. 2016, Peña et al. 2005, Canellas et al., 2010). Humic substances (HS) have been widely recognized as a promoter of plant growth mainly by causing changes in the root, in the architecture and growth dynamics, which result in larger root size, better branching and greater density of root hair with the greater surface area. These substances are formed by the decomposition of plant and animal which are deposited in the soil (Wu et al., 2017, Tan et al., 2014). During this process, the organic material is initially degraded and depolymerized by microbiological action to produce new components with a high degree of dark-colored polymerization (Canellas and Olivares, 2014). Humic substances are classified depending on the separation process used; the significant parts of humus are fulvic acids (AF) which are soluble in acidic medium and HA that are insoluble in acidic medium (Canellas et al., 2015). The structure of the HS (Fig. 1) is highly complex and does not have uniformity in each of its units, which are formed by condensates of aromatic rings containing carboxylic, phenolic, carbonyl, methoxide and aliphatic groups (Gomes de Melo et al., 2016). It is estimated that approximately a quarter of the molecular weight of the HS is due to the oxygenated groups, mainly carboxylic groups that increase with the degree of humification of the organic matter and that can form carboxylates with metals present in the medium. Phenolic groups that are formed in the initial stages of humification and carbonyls groups that by oxidation reactions originate carboxylic groups (Gomes de Melo et al., 2016; Pedrót and Melanie, 2010; Fischer, 2017). The HS play an important role in nature because due to their oxygenated functional groups they participate in cation retention processes that are essential for plants as well as retaining heat on the surface due to their dark color (Pedrót and Melanie, 2010). Current uses of these substances include their activity as fertilizers, their ability to retain useful metals for agriculture and their use

\footnotetext{
${ }^{*}$ Corresponding authors:

Fredy Colpas-Castillo, Faculty of Exact and Natural Sciences, Department of Chemistry, Carbochemical Research Group. University of Cartagena, Colombia. Arnulfo Tarón Dunoyer, Faculty of Engineering, Research Group in Biotechnology, Food (GIBAE). University of Cartagena. Av. Del Consulado Calle 30 \# 48-152, Cartagena-Bolívar. Colombia. E-mail: atarond@unicartagena.edu.co
}

Received: 25 August 2018; $\quad$ Accepted: 22 October 2018 
in the removal of toxic aqueous effluents (Sun et al., 2015; Tang et al., 2014; Kalina et al., 2013). An important source of HS are the low range carbons, which have a high content of oxygenated groups and a part of their structure quite similar to that of HA (Motta \& Santana, 2013). This makes possible the extraction with alkaline solutions of the HS for this type of coals. When the mineral carbons are subjected to moderate oxidation reactions, it is possible to increase the content of HS in their structure, leading to higher percentages of extraction of this type of materials (Zhiyuan et al., 2012; Arslan et al., 2010; Novak et al., 2001). In this study, the effect of the HA obtained from low-rank coal from the Montelibano mine (Córdoba-Colombia) is evaluated in the growth of chili and eggplant plants grown in low fertility soils.

\section{MATERIALS AND METHODS}

\section{Mineral material}

The starting material in this investigation was coal from the mine located in the Montelibano rural area, in the department of Córdoba-Colombia.

\section{Preparation of the sample}

The carbon sample was crushed and sieved to a particle size between 3,1 and 7,1 mm using a sieve with a mesh number of 6 . Subsequently, $100 \mathrm{~g}$ portions of the material were demineralized for $1 \mathrm{~h}$ at room temperature with hydrochloric acid, $5 \mathrm{M}$. Before the oxidation process the material of the carbon sample was subjected to debitumization with an ethanol-benzene mixture $(1: 1 \mathrm{v} / \mathrm{v})$ under reflux for $24 \mathrm{~h}$. The solvent was removed by distillation in Soxhlet and vacuum filtration with distilled water. The remaining moisture was removed by drying at $80^{\circ} \mathrm{C}$ for $12 \mathrm{~h}$ (Anillo et al., 2013). Subsequently, oxidation was carried out in an aqueous medium with $30 \%$ hydrogen peroxide and concentrated acetic acid. This system was heated to $60{ }^{\circ} \mathrm{C}$ and maintained in continuous agitation for $12 \mathrm{~h}$. (Anillo et al., 2013).

\section{Obtaining humic acids}

$5 \mathrm{~g}$ of oxidized carbon was added $100 \mathrm{~mL}$ of $0,1 \mathrm{M} \mathrm{NaOH}$, maintaining this system at $60{ }^{\circ} \mathrm{C}$ for $1 \mathrm{~h}$ in continuous agitation. Subsequently, the solution was filtered under vacuum and $100 \mathrm{~mL}$ of $0,1 \mathrm{M} \mathrm{HCl}$ was added to the filtrate to precipitate the HA. This system was kept at rest for $24 \mathrm{~h}$ and was subsequently centrifuged at $3600 \mathrm{rpm}$ for $10 \mathrm{~min}$. The colloid obtained after the centrifugation was washed with portions of ethanol and finally heated at $100{ }^{\circ} \mathrm{C}$ for one hour to be subjected to different analyzes. The percentage of HA extracted was quantified in relation to the mass of extracted acids obtained from the initial weight of the oxidized carbon samples (Anillo et al., 2013).

\section{Soil strengthening}

This research is used for the cultivation of chili pepper (Capsicum annumm) and eggplant (Solanum melongena), a soil of low fertility provided by the National Apprenticeship Service (SENA) agribusiness sector, fortified with HS and urea. To $200 \mathrm{~g}$ of soil was added directly fertilizer and HA in concentrations of $0.05 \%, 0.1 \%$ and $0.2 \%$ with respect to the amount of soil. For comparison purposes, a control sample was used, which contained fertilizer without the addition of HA.

\section{Tests on plants}

Seeds of chili pepper (Capsicum annum ) and eggplant (Solanum melongena) were sown in the different fortified soils and the control sample. From the first day of sowing, growth was measured at the three-day time intervals until 45 days were completed. The soil samples were hydrated by irrigation. To know effect of HA suggestion observation to root characters on chili pepper and eggplant, by side that yield characters is important to study effect HA on plant.

\section{Statistical analysis}

For the statistical analysis of the results, the measure of plant growth using urea as fertilizer and HA at different concentrations was used as a response variable. The growth measures were analyzed employing an ANOVA (unidirectional) to determine statistically significant differences $(p<0.05)$ between the samples. The software SPSS (version 17.0 for Windows) and the multiple comparison tests of Dunnett test were used. All the tests were carried out in triplicate. In this methods, describe experimental design used, Analysis statistical and procedure research, measurement, example root length, high plant, etc.

\section{RESULTS AND DISCUSSION}

In all the essays, observed the trend of an increase of the root of the plants from the third day of sowings the seeds of the plants (Table 1), being demonstrated that in the case of the plant of chili (Capsicum annuum) to the concentration of $0.05 \%$ of $\mathrm{HA}$ the growth is similar to the control (Fig. 2), whereas to the concentrations of $0.1 \%$ and $0.2 \%$ the length of the root was the double (Table 1$)$. As the days of growth passed, both the control and the concentration of $0.05 \%$, root growth was not observed, unlike that observed in the cultivation soils using concentrations of $0.1 \%$ and $0.2 \%$ of HA. As the days of growth were passing both the control and the concentration of $0.05 \%$ they were kept same way, whereas in the concentrations of $0.1 \%$ and $0.2 \%$ was observed an increase in the length of the root, in the $9^{\text {th }}$ it appreciates a significant increase in the soils of $0.1 \%$ and $0.2 \%$ accenting as the days pass. In fact, after 24 days of growth, the soil fortified with HA at a concentration of $0.1 \%$, showed a tendency to a steady 


\begin{tabular}{|c|c|c|c|c|}
\hline \multirow{2}{*}{$\begin{array}{l}\text { Days of } \\
\text { growth }\end{array}$} & \multicolumn{4}{|c|}{ Soil fertilized with urea and fortified with HA (\%) } \\
\hline & 0.05 & 0.1 & 0.2 & Control \\
\hline 3 & $\mathrm{X}$ & $\mathrm{X}$ & $\mathrm{X}$ & $\mathrm{X}$ \\
\hline 6 & $0,4 \pm 0,005^{a}$ & $1,0 \pm 0,025^{b}$ & $1,5 \pm 0,050^{c}$ & $0,4 \pm 0,002^{a}$ \\
\hline 9 & $2,0 \pm 0,002^{a}$ & $3,3 \pm 0,028^{b}$ & $4,9 \pm 0,060^{c}$ & $1,9 \pm 0,050^{a}$ \\
\hline 12 & $2,5 \pm 0,036^{a}$ & $4,5 \pm 0,023^{b}$ & $6,2 \pm 0,057^{c}$ & $2,5 \pm 0,057^{a}$ \\
\hline 15 & $3,2 \pm 0,011^{a}$ & $6,3 \pm 0,011^{b}$ & $6,5 \pm 0,115^{c}$ & $3,1 \pm 0,028^{a}$ \\
\hline 18 & $3,8 \pm 0,011^{a}$ & $6,8 \pm 0,010^{b}$ & $6,8 \pm 0,005^{b}$ & $3,8 \pm 0,005^{a}$ \\
\hline 21 & $4,3 \pm 0,028^{a}$ & $7,1 \pm 0,011^{b}$ & $7,1 \pm 0,028^{b}$ & $4,4 \pm 0,057^{b}$ \\
\hline 24 & $4,7 \pm 0,025^{a}$ & $7,5 \pm 0,057^{b}$ & $7,5 \pm 0,017^{b}$ & $4,7 \pm 0,015^{a}$ \\
\hline 27 & $4,9 \pm 0,015^{a}$ & $7,6 \pm, 0,086^{b}$ & $7,9 \pm 0,005^{c}$ & $4,7 \pm 0,016^{d}$ \\
\hline 30 & $4,9 \pm 0,017^{a}$ & $7,8 \pm 0,040^{b}$ & $8,2 \pm 0,017^{c}$ & $4,8 \pm 0,005^{a}$ \\
\hline 33 & $4,9 \pm 0,022^{a}$ & $8,0 \pm 0,100^{b}$ & $8,5 \pm 0,028^{c}$ & $4,8 \pm 0,005^{a}$ \\
\hline 36 & $4,9 \pm 0,011^{a}$ & $8,0 \pm 0,100^{b}$ & $8,7 \pm 0,010^{c}$ & $4,8 \pm 0,002^{a}$ \\
\hline 39 & x & $8,0 \pm 0,057^{a}$ & $9,0 \pm 0,028^{b}$ & x \\
\hline 42 & $x$ & $\mathrm{x}$ & $9,3 \pm 0,015$ & $x$ \\
\hline 45 & $x$ & $x$ & $9,5 \pm 0,025$ & $x$ \\
\hline
\end{tabular}

Different letter in the same row differ significantly $(p<0.05)$ (Tukey test). The values represent the mean \pm S.E. $(n=3)$. The growth of the plant is expressed in centimeters $(\mathrm{Cm})$. The $\mathrm{X}$ denotes absence of growth

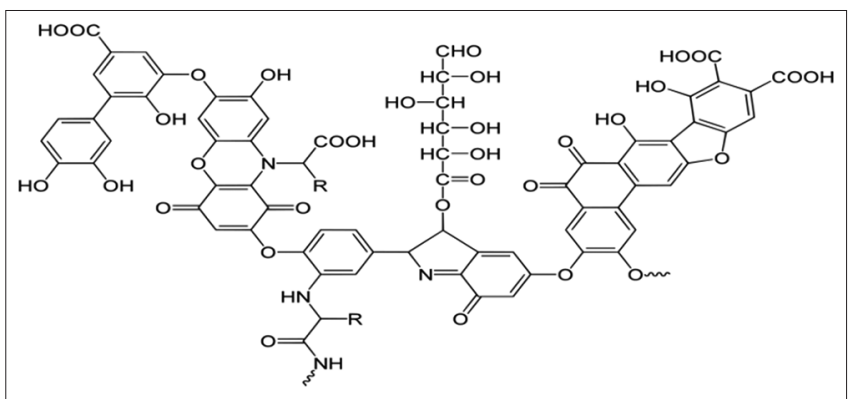

Fig 1. Structure of humic substance.

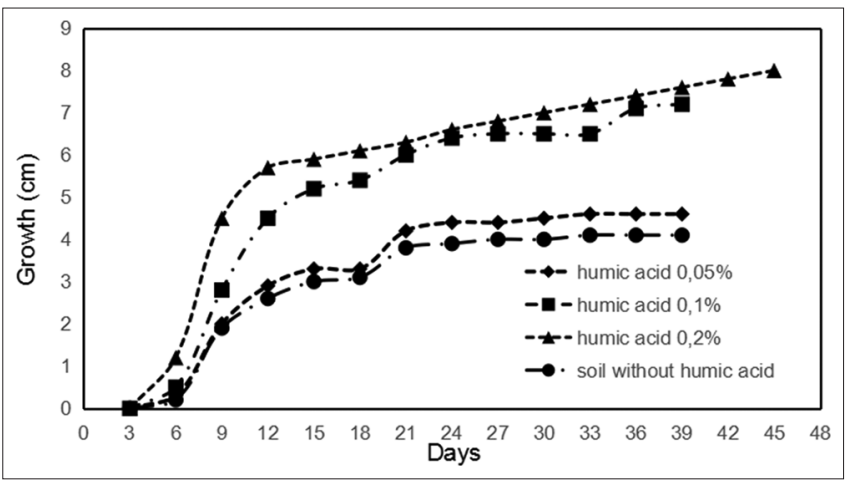

Fig 2. Growth rate of Capsicum annuum (chili pepper) using different concentrations of Humic acid in the soil.

state behaving at that time similar to the control and soil fortified with $0.05 \% \mathrm{HA}$, while growth in soil fortified with $0.2 \% \mathrm{HA}$ increased exponentially (Fig. 2).

The Analysis of variance (ANOVA) showed that there are statistically significant differences in the growth trend of the pepper plant $(p<0.05)$. The multiple comparison tests of Dunnett (Fig. 4a) showed that there is a statistically significant difference $(p<0.05)$ between the control and the concentrations of $0.1 \%$ and $0.2 \%$ of HA. Likewise, the control and the concentration of $0.05 \%$ there was no statistically significant difference $(\mathrm{p}<0.05)$. From the $27^{\text {th }}$ day of growth, the chili pepper plant (Capsicum annumm) cultivated on soils fertilized with urea and fortified with $\mathrm{HA}$ at a concentration of $0.05 \%$ presents. In general terms, slightly higher growth than the plant cultivated in the soil without the addition of HA used as the control.

When each of the concentrations is compared with the control, significant differences are established between this and their concentrations of $0.1 \%$ and $0.2 \%$, while with the concentration of $0.05 \%$, there are no statistically significant differences $(p<0.05)$ as shows the Dunnett test. In the case of the eggplant (Solanum melongena), similar behavior presented in the chili pepper plant, as shown in the growth curve of this plant (Table 2). In the same way, statistically significant differences are presented as shown by the analysis of variance $(p>0.05)$ in the growth of the root of the eggplant. When each of the concentrations is compared, significant differences are established between the control and concentrations of $0.1 \%$ and $0.2 \%$, while with the $0.05 \%$ concentration there are no statistically significant differences $(p<0.05)$ until the ninth $(9)$ day of growth as shown by the Dunnett test (Fig. 4b). But from day twelve (12) of growth if there are statistically significant differences $(p<0.05)$ between them. The results of the HA application test show that all treatments cause significant increases in the total surface area of roots. The increase in leaf area and total root surface, caused by treatments with different types of HA, contributes to the hypothesis of a biostimulant action in plant development (Nebiosso and Picolo, 2012).

According to Barros et al. (2010), HA influence the proliferation of secondary roots and the absorption of nutrients. Besides, constitute an essential factor in the establishment and adaptation of plants in the soil under adverse conditions. Many authors stated that HA in contact with root cells could stimulate the plant development through the mechanism known as acid root growth. The increase of $\mathrm{H}^{+}$ions pumped to the apoplast through the $\mathrm{H}^{+}$ATPase enzyme acidifies the cell wall, making it more flexible.

This behavior facilitates the elongation of the roots and the appearance of active mitosis points, which become emergency points radicular (Canellas and Olivares, 2014; Canellas et al., 2015; Nardi et al., 2016).

Humic substances induce $\mathrm{H}^{+}$-ATPase activity which, in turn, can energize secondary ion transporters and promote 


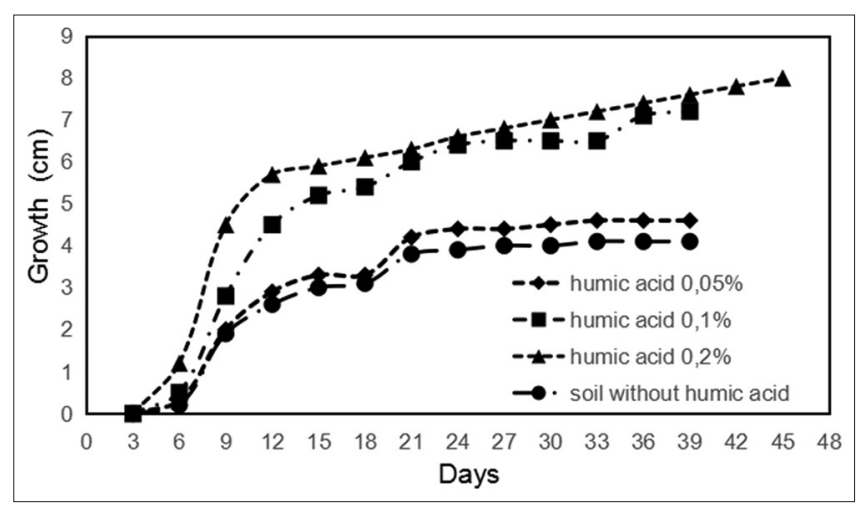

Fig 3. Growth rate of Solanum melongena (Eggplant) using different concentrations of Humic acid in the soil.

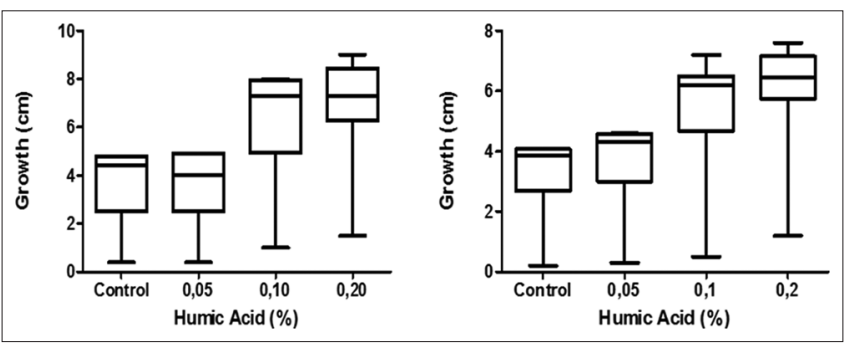

Fig 4. Variance analysis of the growth measurements in the presence of different concentrations of Humic acids compared to the control (without Humic acid). a) Capsicum annuum (chili pepper) and b) Solanum melongena (eggplant).

Table 2: Growth of eggplant plant (Solanum melongena) grown in soils fertilized with urea and different Humic acid concentrations

\begin{tabular}{|c|c|c|c|c|}
\hline \multirow{2}{*}{$\begin{array}{l}\text { Days of } \\
\text { growth }\end{array}$} & \multicolumn{4}{|c|}{ Soil fertilized with urea and fortified with HA (\%) } \\
\hline & 0.05 & 0.1 & 0,2 & Control \\
\hline 3 & $\mathrm{X}$ & $\mathbf{X}$ & $\mathbf{X}$ & $\mathbf{X}$ \\
\hline 6 & $0,3 \pm 0,011^{\mathrm{a}}$ & $0,5 \pm 0,025^{b}$ & $1,2 \pm 0,023^{c}$ & $0,2 \pm 0,005^{a}$ \\
\hline 9 & $2,0 \pm 0,057^{a}$ & $2,8 \pm 0,011^{b}$ & $4,5 \pm 0,015^{c}$ & $1,9 \pm 0,010^{\mathrm{a}}$ \\
\hline 12 & $2,9 \pm 0,017^{a}$ & $4,5 \pm 0,028^{b}$ & $5,7 \pm 0,010^{c}$ & $2,6 \pm 0,026^{d}$ \\
\hline 15 & $3,3 \pm 0,025^{a}$ & $5,2 \pm 0,080^{b}$ & $5,9 \pm 0,057^{c}$ & $3,0 \pm 0,025^{d}$ \\
\hline 18 & $3,3 \pm 0,020^{a}$ & $5,4 \pm 0,057^{b}$ & $6,1 \pm 0,044^{c}$ & $3,1 \pm 0,050^{d}$ \\
\hline 21 & $4,2 \pm 0,086^{a}$ & $6,0 \pm 0,100^{b}$ & $6,3 \pm 0,010^{c}$ & $3,8 \pm 0,015^{d}$ \\
\hline 24 & $4,4 \pm 0,057^{a}$ & $6,4 \pm 0,056^{b}$ & $6,6 \pm 0,014^{c}$ & $3,9 \pm 0,055^{d}$ \\
\hline 27 & $4,4 \pm 0,050^{a}$ & $6,5 \pm 0,005^{b}$ & $6,8 \pm 0,005^{c}$ & $4,0 \pm 0,100^{d}$ \\
\hline 30 & $4,5 \pm 0,015^{a}$ & $6,5 \pm 0,078^{b}$ & $7,0 \pm 0,100^{c}$ & $4,0 \pm 0,050^{d}$ \\
\hline 33 & $4,6 \pm 0,005^{a}$ & $6,5 \pm 0,005^{b}$ & $7,2 \pm 0,172^{\circ}$ & $4,1 \pm 0,023^{d}$ \\
\hline 36 & $4,6 \pm 0,000^{a}$ & $7,1 \pm 0,057^{b}$ & $7,4 \pm 0,005^{\circ}$ & $4,1 \pm 0,020^{d}$ \\
\hline 39 & $4,6 \pm 0,005^{a}$ & $7,2 \pm 0,023^{b}$ & $7,6 \pm 0,003^{c}$ & $4,1 \pm 0,010^{d}$ \\
\hline 42 & X & $\mathrm{x}$ & $7,8 \pm 0,100$ & X \\
\hline 45 & $x$ & $x$ & $8,0 \pm 0,005$ & $x$ \\
\hline
\end{tabular}

Different letters in the same row differ significantly $(p<0.05)$ (Tukey test). The values represent the mean \pm S.E. $(n=3)$. The growth of the plant is expressed in centimeters $(\mathrm{Cm})$. The $\mathrm{X}$ denotes absence of growth

the absorption of nutrients. The transport of nitrate through the plasma membrane is facilitated by ion channels, that is, a secondary active transport, which requires an electrochemical proton gradient generated by the induction of $\mathrm{H}^{+}$-ATPase (primary transport).

\section{CONCLUSIONS}

The critical influence of HA on the physical, chemical and biological properties of the soil has been amply demonstrated and its role in maintaining the growth of plants is recognized. According to the results obtained, HA act as growth biostimulant in pepper plants (Capsicum annum ) and eggplant (Solanum melongena), these changes can be observed in the morphology of the plant. The contact of seeds with humic acid triggers reactions, which lead to increased plant development. This type of research can help overcome the complexity of whether a HS influence plant biology and allows the development of new technologies to increase the growth of plants based on humic matter.

\section{ACKNOWLEDGEMENT}

This study was supported by the Faculty of Engineering and the Faculty of Exact and Natural Sciences of the University of Cartagena. Colombia.

\section{DECLARATIONS OF CONFLICT OF INTEREST}

The authors report no declarations of conflict of interest.

\section{Authors' Contributions}

All the authors contributed to the work presented in this article. Fredy COLPAS and Arnulfo TARON carried out the experiments, designed the research plan, organized the study and contributed to the writing of the manuscript. Jairo MERCADO performed statistical analysis and helped in interpretation of data and discussion of results.

\section{REFERENCES}

Anillo, R., F. Colpas and E. Meza. 2013. Increase in the content of humic acids in a low-range carbon through oxidation with air and with hydrogen peroxide or nitric acid. Quim. Nova. 36: 387-392.

Arslan, G., S. Edebali and E. Pehlivan. 2010. Physical and chemical factors affecting the adsorption of $\mathrm{Cr}(\mathrm{VI})$ via humic acids extracted from brown coals. Desalination. 255: 117-123.

Barros, L., L. Canellas, F. Lopes, and N. Oliveira. 2010. Bioactivity of chemically transformed humic matter from vermin compost on plant root growth. J. Agric. Food Chem. 58: 3681-3688.

Canellas, L. P and F. L. Olivares. 2014. Physiological responses to humic substances as plant growth promoter. Chem. Biol. Techno. Agric. 1: 1-11.

Canellas, L. P., A. Piccolo, L. B Dobbss, R. Spaccini, F. L Olivares, D. B Zandonadi and A. R Façanha. 2010. Chemical composition and bioactivity properties of size-fractions separated from a vermicompost humic acid. Chemosphere. 78: 457-466.

Canellas, L. P., F. L. Olivares, N. O. Aguilar, D.L. Jones, A. Nebbioso, P. Mazzei and A. Piccolo. 2015. Humic and fulvic acids as biostimulants in horticulture. Sci. Horticulturae. 196: 15-27. 
Fischer, T. 2017. Humic supramolecular structures have polar surfaces and unpolar cores in native soil. Chesmosphere. 183: 437-443.

Gomes de Melo, B., L. Lopes and M. Andrade. 2016. Humic acids: Structural properties and multiple functionalities for novel technological developments materials. Sci. Eng. C. 62: 967-974.

Novak, J., J. Kozler, J. Pavel, J. Cezikova, T. Venceslava and L. Madronova. 2001. Humic acids from coals of the NorthBohemian coal field I. Preparation and characterization. React. Funct. Polym. 47: 101-109.

Kalina, M., M. Klučáková and P. Sedláček. 2013. Utilization of fractional extraction for characterization of the interactions between humic acids and metals. Geoderma. 208: 92-98.

Motta, F. and M. Santana. 2013. Production of humic acids from oil palm empty fruit bunch by submerged fermentation with Trichoderma viride: Cellulosic substrates and nitrogen sources. Biotechnol. Prog. 29: 631-637.

Nardi, S., D. Pizzeghello, M. Schiavon and A. Ertani. 2016. Plant biostimulants: Physiological responses induced by protein hydrolyzed-based products and humic substances in plant metabolism. Sci. Agric. 73: 18-23.

Nebiosso, A. and A. Piccolo. 2012. Advances in humeomic: Enhanced structural identification of humic molecules after size fractionation of a soil humic acid. Anal. Chim. Acta 720: 77-90.

Pantoja, M., Y. Almanza and N. Valero. 2016. Evaluación del efecto auxin-like de ácidos húmicos en maíz mediante análisis digital de imágenes. Rev. Act. Divulg. Cient. 19: 361-369.

Pedrót, M. and A. Mélanie. 2010. Dynamic structure of humic substances: Rare earth elements as a fingerprint. J. Colloid Interface Sci. 345: 206-213.

Peña, E. M., J. Havel and J. Patočka. 2005. Humic substancescompounds of still unknown structure: Applications in agriculture, industry, environment, and biomedicine. J. Appl. Biomed. 3: 13-24.

Sun, Z., B. Tang and H. Xie. 2015. Treatment of waste gases by humic acid. Energy Fuels. 29: 1269-1278.

Tang, W.W., G.M. Zeng, J.L. Gong, J. Liang, P. Xu, C. Zhang and B. B. Huang. 2014. Impact of humic/fulvic acid on the removal of heavy metals from aqueous solutions using nanomaterials: $A$ review. Sci. Total Environ. 468-469: 1014-1027.

Tan K. H. 2014. Humic Matter in Soil and the Environment: Principles and Controversies. CRC Press.

Wu, J., Y. Zhao, H. Qi, X. Zhao, T. Yang, Y. Du, H. Zhang and Z. Wei. 2017. Identifying the key factors that affect the formation of humic substance during different materials composting. Bioresource Technol. 244(1): 1193-1196.

Zhiyuan, Y., G. Liang and R. Pan. 2012. Preparation of nitric humic acid by catalytic oxidation from Guizhou coal with catalysts. Int. J. Mining Sci. Technol, 22: 75-78. 